
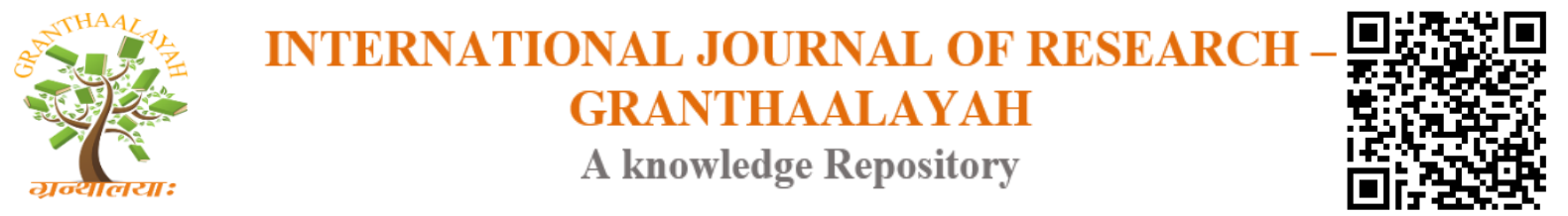

Science

\title{
DIMINISHING OF TRUE POWER LOSS BY APIDAE ALGORITHM
}

\author{
Dr K. Lenin *1 \\ ${ }^{* 1}$ Professor, Department of EEE, Prasad V.Potluri Siddhartha Institute of Technology, Kanuru, \\ Vijayawada, Andhra Pradesh -520007, India
}

\begin{abstract}
In this paper, Apidae Algorithm (AA) is proposed for solving reactive power problem. Apidae Algorithm, inspired from the natural foraging behaviour of Apidae, \& it has been utilized to solve the reactive power problem. The AA algorithm carry out the intensified neighbourhood search united with a random mode exploration search. Efficiency of the projected Apidae Algorithm (AA) is validated by evaluating in standard IEEE 118, 300 bus test systems. Simulated outcomes shows that active power loss has been reduced with variables are within the limits.
\end{abstract}

Keywords: Optimal Reactive Power; Transmission loss; Apidae algorithm.

Cite This Article: Dr K. Lenin. (2018). "DIMINISHING OF TRUE POWER LOSS BY APIDAE ALGORITHM." International Journal of Research - Granthaalayah, 6(12), 84-89. https://doi.org/10.29121/granthaalayah.v6.i12.2018.1080.

\section{Introduction}

Main aim of this work is to reduce the real power loss \& to keep the variables within the limits. Till now various conventional techniques [1-6] have been applied to solve the problem. Major difficulties which have been found in conventional methods are overcome by using Evolutionary techniques [7-18]. But evolutionary algorithms are also stuck into local optimal solution. In this work Apidae Algorithm, is applied for solving reactive power optimization problem. Apidae Algorithm, inspired from the natural foraging behaviour of Apidae, \& it has been utilized to solve the reactive power problem. The AA algorithm carry out the intensified neighbourhood search united with a random mode exploration search. Efficiency of the projected Apidae Algorithm (AA) is validated by evaluating in standard IEEE 118, 300 bus test systems. Simulated outcomes shows that active power loss has been reduced with variables are within the limits.

\section{Problem Formulation}

\section{Objective Function}

A. Real Power Loss

Objective of the problem is to reduce the true power loss: 
$\mathbf{F}=\mathbf{P}_{\mathrm{L}}=\sum_{\mathrm{k} \in \mathrm{Nbr}} \mathbf{g}_{\mathrm{k}}\left(\mathrm{V}_{\mathrm{i}}^{2}+\mathrm{V}_{\mathrm{j}}^{2}-2 \mathbf{V}_{\mathrm{i}} \mathrm{V}_{\mathrm{j}} \cos \theta_{\mathrm{ij}}\right)$

\section{B. Amplification of Voltage Profile}

Voltage deviation given as follows:

$F=P_{L}+\omega_{v} \times$ Voltage Deviation

Voltage deviation given by:

$$
\text { Voltage Deviation } \quad=\sum_{\mathbf{i}=1}^{\mathrm{Npq}}\left|\mathbf{V}_{\mathbf{i}}-\mathbf{1}\right|
$$

\section{Constraint (Equality)}

$$
\mathbf{P}_{G}=\mathbf{P}_{\mathbf{D}}+\mathbf{P}_{\mathbf{L}}
$$

\section{Constraints (Inequality)}

In equality constraints are given by,

$$
\begin{aligned}
& \mathbf{P}_{\text {gslack }}^{\min } \leq \mathbf{P}_{\text {gslack }} \leq \mathbf{P}_{\text {gslack }}^{\max } \\
& \mathbf{Q}_{\mathrm{gi}}^{\min } \leq \mathbf{Q}_{\mathrm{gi}} \leq \mathbf{Q}_{\mathrm{gi}}^{\max }, \mathbf{i} \in \mathbf{N}_{\mathrm{g}} \\
& \mathbf{V}_{\mathbf{i}}^{\min } \leq \mathbf{V}_{\mathbf{i}} \leq \mathbf{V}_{\mathbf{i}}^{\max }, \mathbf{i} \in \mathbf{N} \\
& \mathbf{T}_{\mathbf{i}}^{\text {min }} \leq \mathbf{T}_{\mathbf{i}} \leq \mathbf{T}_{\mathbf{i}}^{\text {max }}, \mathbf{i} \in \mathbf{N}_{\mathbf{T}} \\
& \mathbf{Q}_{c}^{\min } \leq \mathbf{Q}_{c} \leq \mathbf{Q}_{\mathrm{C}}^{\max }, \mathbf{i} \in \mathbf{N}_{\mathrm{C}}
\end{aligned}
$$

\section{Deeds and Algorithm of Apidae}

A colony of Apidae can exploit a huge number of food sources in big fields and they can fly up to $12 \mathrm{~km}$ to exploit food sources [19-26]. The colony utilize about one-quarter of its members as searcher Apidae. The foraging process begins with searching out hopeful flower patches by scout Apidae. The colony keeps a proportion of the scout Apidae during the harvesting season. When the scout Apidae has found a flower area, they will look further in hope of finding an even superior one. The scout Apidae search for the better patches randomly. The scout Apidae notify their peers waiting in the hive about the eminence of the food source, based amongst other things, on sugar levels. The scout Apidae dump their nectar and go to the dance floor in front of the hive to converse to the other Apidae by performing their dance, known as the waggle dance. The waggle dance is named based on the wagging run, which is used by the scout Apidae to communicate information 
about the food source to the rest of the colony. The scout Apidae presents the following information by means of the waggle dance: the quality of the food source, the distance of the source from the hive and the direction of the source.

Quantity of scout Apidae in the selected patches - $n$

Quantity of best patches in the selected patches - $\mathrm{m}$

Quantity of elite patches in the selected best patches- e

Quantity of recruited Apidae in the elite patches -nep

Quantity of recruited Apidae in the non-elite best patches- $n s p$

The size of neighbourhood for each patch - ngh

Quantity of iterations- Maxiter

Variation between value of the first and last iterations- diff

Create the initial population size as $n, m, e$, nep, set $n s p, n g h$, MaxIter, and set the error limit as Error.

$i=0$

Engender initial population.

Determine Fitness value of initial population.

Organize the preliminary population based on the fitness result.

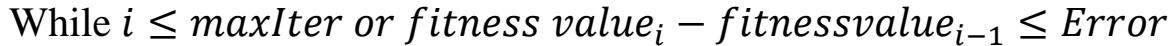

i. $\quad i=i+1$;

ii. Prefer the elite patches and non-elite best patches for neighbourhood search.

iii. Employ the forager Apidae to the elite patches and non-elite best patches.

iv. Compute the fitness value of each patch.

v. Organize the results based on their fitness.

vi. Allocate the rest of the Apidae for global search to the non-best locations.

vii. Compute the fitness value of non-best patches.

viii. Organize the overall results based on their fitness.

ix. Run the algorithm until stop criteria met.

End

The primary move is to implement the shrinking approach. This approach works on a best site after a definite number of repetitions. The approach works until the repetition stops. If, in spite of the shrinking approach, the number of repetitions still increases for a definite number of iterations, then an augmentation approach is utilized. Finally, if the number of repetitions still increases for a number of iterations after the use of the augmentation approach, then that site is abandoned and a new site will be generated. Koc [24] utilized the following parameter for shrinking the neighbourhood size and site abandonment approach: neighbourhood size $=n g h$, the shrinking constant $=s c$, the abandoned sites $=$ aband_site. In this study four more parameters are introduced. The first is the number of repetitions for each site, denoted as keep_point. The keep_point records the number of repetitions for all the repetitive results for best sites. The second parameter is called the "Repetition Number for the shrinking" is denoted as rep_nshr; the number of shrinking is the number of repetitions necessary to start the shrinking strategy, as given in Equations (10) and (11). The parameter is the "Repetition Number for the enhancement" is denoted as rep_nenh. This parameter defines the number of repetitions until the end of the shrinking process, and the beginning of the enhancement process as shown in Equations (10) and (12). The enhancement 
process works until the number of the repetitions is equal to the rep_naban, which denotes the "Repetition Number for the abandonment process". Hence a non-productive site is abandoned and it is stored in aband_site list. If there is no better solution than the abandoned site at the end of the searching process, this is the final solution.

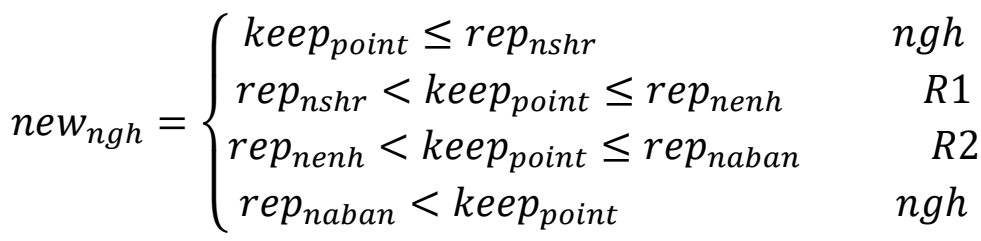

$R 1=n g h-\left(n g h * \frac{\left(\text { keep }_{\text {point }}-\text { rep_nshr }_{-}\right)}{100} * S C\right)$

$R 2=n g h+\left(n g h * \frac{\left(\text { keep }_{\text {point }}-\text { rep_nenh }_{-}\right)}{100} * S C\right)$

Simulation Results

At first IEEE 118 bus system [31] is used as test system to validate the performance of the proposed Apidae algorithm. Table 1 shows limit values.

Table 1: Limitation OF REACTIVE power sources

\begin{tabular}{|l|l|l|l|l|l|l|l|}
\hline Bus number & 5 & 34 & 37 & 44 & 45 & 46 & 48 \\
\hline Maximum value of QC & 0.000 & 14.000 & 0.000 & 10.000 & 10.000 & 10.000 & 15.000 \\
\hline Minimum value of QC & -40.000 & 0.000 & -25.000 & 0.000 & 0.000 & 0.000 & 0.000 \\
\hline Bus number & 74 & 79 & 82 & 83 & 105 & 107 & 110 \\
\hline Maximum value of QC & 12.000 & 20.000 & 20.000 & 10.000 & 20.000 & 6.000 & 6.000 \\
\hline Minimum value of QC & 0.000 & 0.000 & 0.000 & 0.000 & 0.000 & 0.000 & 0.000 \\
\hline
\end{tabular}

Table 2 show the comparison of results.

Table 2: evaluation of results

\begin{tabular}{|l|l|l|l|l|}
\hline $\begin{array}{l}\text { Active power loss - } \\
\text { Minimum \& Maximum } \\
\text { values }\end{array}$ & $\begin{array}{l}\text { Methodology - } \\
\text { BBO } \\
{[\mathbf{3 2}]}\end{array}$ & $\begin{array}{l}\text { Methodology } \\
\text { ILSBBO/ } \\
\text { strategy1 } \\
{[\mathbf{3 2}]}\end{array}$ & $\begin{array}{l}\text { Methodology } \\
\text { ILSBBO/ } \\
\text { strategy1 } \\
{[\mathbf{3 2}]}\end{array}$ & AA \\
\hline Minimum value & 128.770 & 126.980 & 124.780 & 123.002 \\
\hline Maximum value & 132.640 & 137.340 & 132.390 & 126.106 \\
\hline Average value & 130.210 & 130.370 & 129.220 & 124.284 \\
\hline
\end{tabular}

Finally, IEEE 300 bus system [31] is used as test system to validate the performance of the proposed Apidae algorithm. Table 3 shows the comparison of real power loss obtained after optimization.

Table 3: comparison of real power loss

\begin{tabular}{|l|l|l|l|l|}
\hline Parameter & Method EGA [30] & Method EEA [30] & Method CSA [29] & AA \\
\hline PLOSS (MW) & 646.2998 & 650.6027 & 635.8942 & 627.1054 \\
\hline
\end{tabular}




\section{Conclusion}

Apidae Algorithm, inspired from the natural foraging behaviour of Apidae, \& it successfully solved the optimal reactive power problem. The AA algorithm carry out the intensified neighbourhood search united with a random mode exploration search. Efficiency of the projected Apidae Algorithm (AA) is validated by evaluating in standard IEEE 118, 300 bus test systems. Simulated outcomes shows that active power loss has been reduced with variables are within the limits. The simulation results presented in previous section prove the ability of AA approach to arrive at near global optimal solution.

\section{References}

[1] K. Y. Lee, "Fuel-cost minimisation for both real and reactive-power dispatches," Proceedings Generation, Transmission and Distribution Conference, vol/issue: 131(3), pp. 85-93, 1984.

[2] N. I. Deeb, "An efficient technique for reactive power dispatch using a revised linear programming approach," Electric Power System Research, vol/issue: 15(2), pp. 121-134, 1988.

[3] M. R. Bjelogrlic, M. S. Calovic, B. S. Babic, et. al.," Application of Newton's optimal power flow in voltage/reactive power control", IEEE Trans Power System, vol. 5, no. 4, pp. 1447-1454, 1990.

[4] S. Granville, "Optimal reactive dispatch through interior point methods," IEEE Transactions on Power System, vol/issue: 9(1), pp. 136-146, 1994.

[5] N. Grudinin, "Reactive power optimization using successive quadratic programming method," IEEE Transactions on Power System, vol/issue: 13(4), pp. 1219-1225, 1998.

[6] Wei Yan, J. Yu, D. C. Yu and K. Bhattarai," A new optimal reactive power flow model in rectangular form and its solution by predictor corrector primal dual interior point method", IEEE Trans. Pwr. Syst., vol.21, no.1, pp.61-67, 2006.

[7] Aparajita Mukherjee, Vivekananda Mukherjee, "Solution of optimal reactive power dispatch by chaotic krill herd algorithm", IET Gener. Transm. Distrib,, Vol. 9, Issue. 15, pp. 2351-2362, 2015.

[8] Hu, Z., Wang, X. \& Taylor, G. Stochastic optimal reactive power dispatch: Formulation and solution method. Electr. Power Energy Syst., vol. 32, pp. 615-621. 2010.

[9] Mahaletchumi A/P Morgan, Nor Rul Hasma Abdullah, Mohd Herwan Sulaiman, Mahfuzah Mustafa and Rosdiyana Samad, "Computational intelligence technique for static VAR compensator (SVC) installation considering multi-contingencies (N-m)", ARPN Journal of Engineering and Applied Sciences, VOL. 10, NO. 22, DECEMBER 2015.

[10] Mohd Herwan Sulaiman, Zuriani Mustaffa, Hamdan Daniyal, Mohd Rusllim Mohamed and Omar Aliman, "Solving Optimal Reactive Power Planning Problem Utilizing Nature Inspired Computing Techniques”, ARPN Journal of Engineering and Applied Sciences, VOL. 10, NO. 21,, pp.97799785. NOVEMBER 2015

[11] Mohd Herwan Sulaiman, Wong Lo Ing, Zuriani Mustaffa and Mohd Rusllim Mohamed, "Grey Wolf Optimizer for Solving Economic Dispatch Problem with Valve-Loading Effects", ARPN Journal of Engineering and Applied Sciences, VOL. 10, NO. 21,, pp. 9796-9801, NOVEMBER 2015.

[12] Pandiarajan, K. \& Babulal, C. K., "Fuzzy harmony search algorithm based optimal power flow for power system security enhancement”. International Journal Electric Power Energy Syst., vol. 78, pp. 72-79. 2016.

[13] Mustaffa, Z., Sulaiman, M.H., Yusof, Y., Kamarulzaman, S.F., "A novel hybrid metaheuristic algorithm for short term load forecasting", International Journal of Simulation: Systems, Science and Technology, Volume 17, Issue 41, Pages 6.1-6.6. 2017.

[14] Sulaiman, M.H., Mustaffa, Z., Mohamed, M.R., Aliman, O., "An application of multi-verse optimizer for optimal reactive power dispatch problems", International Journal of Simulation: Systems, Science and Technology, Volume 17, Issue 41, Pages 5.1-5.5. 2017. 
[15] Mahaletchumi A/P Morgan, Nor Rul Hasma Abdullah, Mohd Herwan Sulaiman,Mahfuzah Mustafa and Rosdiyana Samad, "Multi-Objective Evolutionary Programming (MOEP) Using Mutation Based on Adaptive Mutation Operator (AMO) Applied For Optimal Reactive Power Dispatch", ARPN Journal of Engineering and Applied Sciences, VOL. 11, NO. 14, JULY 2016.

[16] Rebecca Ng Shin Mei, Mohd Herwan Sulaiman, Zuriani Mustaffa, "Ant Lion Optimizer for Optimal Reactive Power Dispatch Solution", Journal of Electrical Systems, "Special Issue AMPE2015", pp. 68-74.2016.

[17] Mahaletchumi Morgan, Nor Rul Hasma Abdullah, Mohd Herwan Sulaiman, Mahfuzah Mustafa, Rosdiyana Samad, "Benchmark Studies on Optimal Reactive Power Dispatch (ORPD) Based Multi-objective Evolutionary Programming (MOEP) Using Mutation Based on Adaptive Mutation Adapter (AMO) and Polynomial Mutation Operator (PMO)", Journal of Electrical Systems, 12-1, 2016.

[18] Rebecca Ng Shin Mei, Mohd Herwan Sulaiman, Zuriani Mustaffa, Hamdan Daniyal, "Optimal Reactive Power Dispatch Solution by Loss Minimization using Moth-Flame Optimization Technique", Applied Soft Computing, Volume 59, October, Pages 210-222, 2017.

[19] Pham, D.T.; Ghanbarzadeh, A.; Koc, E.; Otri, S.; Rahim, S.; Zaidi, M. The Bees Algorithm, Technical Note; Manufacturing Engineering Center, Cardiff University: Cardiff, UK, 2005.

[20] Seeley, T.D. The Wisdom of the Hive: The Social Physiology of Honey Bee Colonies; Harvard University Press: Cambridge, MA, USA, 2009.

[21] Gould, J.L.; Gould, C.G. The Honey Bee; Scientific American Library: New York, NY, USA, 1988.

[22] Von Frisch, K. Bees: Their Vision, Chemical Senses, and Language; Cornell University Press: Ithaca, NY, USA, 1950.

[23] Huang, Z. Behavioral Communications: The Waggle Dance. Available online: http://photo.bees.net/ biology/ch6/dance2.html (accessed on 29 June 2013).

[24] Koc, E. The Bees Algorithm Theory, Improvements and Applications. Ph.D Thesis, Cardiff University, Cardiff, UK, 2010.

[25] Yuce, B. Novel Computational Technique for Determining Depth Using the Bees Algorithm and Blind Image Deconvolution. Ph.D Thesis, Cardiff University, Cardiff, UK, 2012.

[26] Baris Yuce, Michael S. Packianather, Ernesto Mastrocinque, Duc Truong Pham and Alfredo Lambiase "Honey Bees Inspired Optimization Method": The Bees Algorithm Insects 2013, 4, 646662; doi:10.3390/insects4040646.

[27] Wu.Q.H,Y.J.Cao,andJ.Y.Wen,(1998), “Optimal reactive power dispatch using an adaptive genetic algorithm”, Int.J.Elect.Power Energy Syst. Vol 20. Pp. 563-569.

[28] Zhao. B,C. X.Guo, and Y.J.CAO,(2005),"Multiagent-based particle swarm optimization approach for optimal reactive power dispatch", IEEE Trans. Power Syst. Vol. 20, no. 2, pp. 1070-1078.

[29] S. Surender Reddy, "Optimal Reactive Power Scheduling Using Cuckoo Search Algorithm", International Journal of Electrical and Computer Engineering, Vol. 7, No. 5, pp. 2349-2356. 2017

[30] S.S. Reddy, et al., "Faster evolutionary algorithm based optimal power flow using incremental variables", Electrical Power and Energy Systems, vol. 54, pp. 198-210, 2014.

[31] IEEE, "IEEE 118, 300 -test systems", (1993), http://www.ee.washington.edu/trsearch/pstca/.

[32] Jiangtao Cao, Fuli Wang and Ping Li, "An Improved Biogeography-based Optimization Algorithm for Optimal Reactive Power Flow", International Journal of Control and Automation Vol.7, No.3 (2014), pp.161-176.

*Corresponding author.

E-mail address: gklenin@ gmail.com 